\title{
Prevalence of Mineral Bone Disorders in Chronic Kidney Disease Patients
}

\author{
Tapas Ranjan Behera ${ }^{1}$, Bishwaranjan Mohanty ${ }^{1 *}$, Alisha Sahu², Sujata Naik ${ }^{3}$, Jatindra Nath Mohanty ${ }^{4}$ \\ ${ }^{1}$ Department of Nephrology, IMS and SUM hospital, Siksha "O" Anusandhan University (Deemed to be), K8, Kalinga nagar, Bhubaneswar-751003, Odisha, \\ India, ${ }^{2}$ Department of Anaesthesia \& critical care, IMS and SUM hospital, Siksha "O" Anusandhan University (Deemed to be), K8, Kalinga \\ nagar,Bhubaneswar-751003, Odisha, India, ${ }^{3}$ Department of Pathology, IMS and SUM hospital, Siksha "O" Anusandhan University (Deemed to be), K8, \\ Kalinga nagar,Bhubaneswar-751003, Odisha, India, "Medical Research Laboratory, IMS and SUM hospital, Siksha "O" Anusandhan University (Deemed \\ to be), K8, Kalinga nagar,Bhubaneswar-751003, Odisha, India.
}

\section{Abstract}

Background: Chronic kidney disease (CKD) is a progressive loss in renal function which involves in deterioration in mineral homeostasis with disruption of normal serum and tissue concentration of phosphorus and calcium. Also changes in circulating levels of hormonesparathyroid hormone $(\mathrm{PTH})$, calcitriol $(1,25(\mathrm{OH}) 2 \mathrm{D})$, and fibroblast growth factor-23 (FGF-23). Here our aim is to study the prevalence of markers associated with MBD in CKD stage 3-5 patients. Patients with CKD stage 3-5 were included in this observational study with all necessary parameter. X-RAY abdomen and echocardiography was done to look for evidence of vascular and valvular calcification respectively. Statistical analysis was done using SPSS software. A total of 170 patients (128 males, 42 females) $(\mathrm{M}: \mathrm{F}=3: 1)$ were included in this study with a mean age of 50.54 years. Among CKD stages 3 to 5, the prevalence of hypocalcemia was $22.2 \%, 33.3 \%$ \& $48.9 \%$, hyperphosphatemia was $11.1 \%, 25.5 \%$ \& $63 \%$, hyperparathyroidism was $48.1 \%, 67.3 \%$ \& $89.1 \%$, high total alkaline phosphatase was $0 \%$, $5.9 \%$ \& 45.7\% , low 25-OH-vit D was 59.2\%, 70.6\% \& 79.4\% respectively. Low $25(\mathrm{OH}) \mathrm{D}$ levels, hyperparathyroidism, and hyperphosphatemia were the noticeable markers of CKD-MBD in our patients. Mineral bone disorder are common in CKD patients which start in early CKD stages \& worsen with disease progression that causes morbidity and decreased quality of life.

Keywords: CKD, MBD, Hyperparathyroidism, Hyperphosphatemia, Hypocalcemia.

Corresponding Author: Dr. Bishwaranjan Mohanty, Department of Nephrology, IMS and SUM hospital, Siksha "O” Anusandhan University (Deemed to be), K8, Kalinga nagar, Bhubaneswar-751003, Odisha, India.

Received: October 2019

Accepted: October 2019

\section{Introduction}

Chronic kidney disease (CKD) has a prevalence of 5-10\% of the world population. ${ }^{[1]}$ Patients with CKD have high rates of total and cardiovascular morbidity and mortality. Abnormalities in levels of mineral metabolites and regulators, such as calcium, phosphate, parathyroid hormone, fibroblast growth factor-23 and vitamin D have been linked to the progression of cardiovascular disease and poor outcomes. ${ }^{[2]}$ These mineral and endocrine capacities are basically significant in the guideline of both starting bone formation during development and bone structure \& function all through adulthood (modeling and remodeling of bone). ${ }^{[3]}$ As kidney function declines, there is a progressive deterioration in mineral homeostasis with a disruption of normal serum and tissue concentrations of phosphorus and calcium and changes in circulating levels of hormones. These include parathyroid hormone (PTH), 25-hydroxy vitamin D, 1,25-dihydroxyvitamin $\mathrm{D}$ and other vitamin $\mathrm{D}$ metabolites, fibroblast growth factor-23 (FGF-23), and growth hormone. The ability of the kidneys to appropriately excrete a phosphate load is diminished when GFR falls below 60, leading to hyperphosphatemia, elevated $\mathrm{PTH}$, decreased $1,25(\mathrm{OH})_{2} \mathrm{D}$ with associated elevations in the levels of FGF23. The conversion of $25(\mathrm{OH}) \mathrm{D}$ to $1,25(\mathrm{OH})_{2} \mathrm{D}$ is impaired, reducing intestinal calcium absorption and increasing PTH. The kidneys fail to respond adequately to PTH, which normally promotes phosphaturia and calcium absorption, or to FGF-23, which also enhances phosphate excretion. In addition, there is evidence at the tissue level of a down regulation of vitamin $\mathrm{D}$ receptor and of resistance to the actions of PTH. Therapy is generally focused on correcting biochemical and hormonal abnormalities in an effort to limit their consequences. The mineral and endocrine functions disrupted in CKD are critically important in the regulation of both initial bone formations during growth (bone modeling). As a result, bone abnormalities are found almost universally in patients with CKD requiring dialysis (stage 5D), and in the majority of patients with CKD stages 3-5. More recently, there has been an increase concern of extra skeletal calcification that may result from the deranged mineral and bone metabolism of CKD and from the therapies used to correct these abnormalities. ${ }^{[4]}$

Numerous cohort studies have shown associations between disorders of mineral metabolism and fractures, 
cardiovascular disease and mortality. These observational studies have broadened the focus of CKD related mineral and bone disorders (MBDs) to include cardiovascular disease which is the leading cause of death in patients at all stages of CKD. All three of these processes (abnormal mineral metabolism, abnormal bone and extra skeletal calcification) are closely interrelated and together make a major contribution to the morbidity and mortality of patients with CKD. So we aim here to reveal the prevalence of markers of MBD in CKD stage 3-5 patients.

\section{Subjects and Methods}

This prospective single centre study was conducted in department of nephrology, IMS \& SUM hospital between October 2017 to march 2019. All CKD patients from stage 35 were included. Likewise Patients having pre-existing systemic diseases like SLE/RA, liver disease, patients on steroids or other drugs which have effect on bone metabolism like calcium, phosphate binders, vit D, bisphosphonates, patients with primary bone diseases, patients on maintenance hemodialysis and $\mathrm{h} / \mathrm{o}$ fracture in last 6 months are excluded from this study.

Glomerular filtration rate (eGFR) was estimated based on Cockroaft-Gault formula. Serum creatinine, albumin, calcium, phosphate $\left(\mathrm{PO}_{4}\right)$, TAP, hemoglobin, uric acid, and urinary protein excretion were measured using standard laboratory techniques. Plasma intact parathormone (iPTH) was measured using the solid phase, two-site chemiluminescent enzyme-labeled immunometric assay. Plasma 25-OH vitamin D (25-vitD) assay was done using the radioimmunometric assay. Radiological survey like lateral $\mathrm{X}$-ray of skull, abdomen and 2D echocardiography was carried out to detect vascular and valvular calcification respectively. Statistical analyses are performed using SPSS software. Various parameters of the whole group were analyzed as well as the parameters were compared between the groups. Parametric variables were compared using unpaired $t$-test and Mann-Whitney Rank Sum test. Nonparametric variables were compared using Chi-square test. At $P$ value $<0.05$ was taken as significant.

\section{Results}

The total 170 cases, out of which $128(75.3 \%)$ were males and $42(24.7 \%)$ were females were taken in this hospitalbased cross-sectional observational study. Male: female ratio is 3:1. Majority of patients were middle aged, i.e, in 41-60 years age group with mean age of 50.54 years, Out of all, 46 $\%$ patients were diabetic and $86 \%$ patients were hypertensive.

\section{Table 1: Distribution of calcium levels in different stage CKD} patients

\begin{tabular}{|c|c|c|c|c|}
\hline & \multicolumn{3}{|c|}{ Calcium } & \multirow[b]{2}{*}{ Total } \\
\hline & $<8.5$ & $8.5-10.5$ & $>10.5$ & \\
\hline $\begin{array}{rc}\text { CKD } 3 & \text { count } \\
& \% \text { within CKD } 3\end{array}$ & $\begin{array}{l}6 \\
22.2 \%\end{array}$ & $\begin{array}{l}21 \\
77.8 \%\end{array}$ & $\begin{array}{ll}0 \\
0 \%\end{array}$ & $\begin{array}{l}27 \\
100 \% \\
\end{array}$ \\
\hline $\begin{array}{cc}\text { CKD } 4 & \text { count } \\
& \% \text { within CKD } 4\end{array}$ & $\begin{array}{l}17 \\
33.3 \%\end{array}$ & $\begin{array}{l}32 \\
62.8 \%\end{array}$ & $\begin{array}{ll}2 \\
3.9 \% \\
\end{array}$ & $\begin{array}{ll}51 \\
100 \% \\
\end{array}$ \\
\hline $\begin{array}{lc}\text { CKD } 5 \quad \text { count } \\
\\
\\
\% \text { within CKD } 5\end{array}$ & $\begin{array}{l}45 \\
48.9 \%\end{array}$ & $\begin{array}{l}47 \\
51.1 \%\end{array}$ & $0 \%$ & $\begin{array}{l}92 \\
100 \%\end{array}$ \\
\hline $\begin{array}{cc}\text { Total } & \text { count } \\
& \% \text { within CKD }\end{array}$ & $\begin{array}{l}68 \\
40.0 \%\end{array}$ & $\begin{array}{l}100 \\
58.8 \%\end{array}$ & $\begin{array}{l}2 \\
1.2 \% \\
\end{array}$ & $\begin{array}{l}170 \\
100 \% \\
\end{array}$ \\
\hline
\end{tabular}

In stage 3 CKD patients ( $\mathrm{n}=27)$, majority $(77.8 \%)$ had calcium levels in the normal range, only $22.2 \%$ had calcium below normal range. In stage 4 patients $(n=51)$, calcium levels were in the normal range in $62.8 \%$ of patients, $33.3 \%$ had calcium below normal range and $3.9 \%$ had higher calcium levels than normal. In stage 5 CKD patients (92), calcium levels were in the normal range in $51.1 \%$ of patients, while a significant number of patients $(48.9 \%)$ had low levels of calcium(Table 1). The results were found statistically significant with $\mathrm{p}$ value $<0.05$. Elevated phosphorus levels $(>4.5 \mathrm{mg} / \mathrm{dl})$ in $11.1 \%$ patients of CKD stage 3, 25.5\% patients of CKD stage 4 and $63 \%$ patients of CKD stage 5 were found which is also statistically significant. [Table 2].

\begin{tabular}{|c|c|c|c|}
\hline & \multicolumn{2}{|c|}{ Phosphorus } & \multirow[b]{2}{*}{ Total } \\
\hline & $2.5-4.5$ & $>4.5$ & \\
\hline $\begin{aligned} \text { CKD } 3 & \text { count } \\
& \text { \%within CKD 3 }\end{aligned}$ & $\begin{array}{l}24 \\
88.9 \%\end{array}$ & $\begin{array}{l}3 \\
11.1 \%\end{array}$ & $\begin{array}{l}27 \\
100 \%\end{array}$ \\
\hline $\begin{aligned} \text { CKD } 4 & \text { count } \\
& \text { \%within CKD } 4\end{aligned}$ & $\begin{array}{l}38 \\
74.5 \%\end{array}$ & $\begin{array}{l}13 \\
25.5 \%\end{array}$ & $\begin{array}{l}51 \\
100 \%\end{array}$ \\
\hline $\begin{aligned} \text { CKD } 5 & \text { count } \\
& \% \text { within CKD } 5\end{aligned}$ & $\begin{array}{ll}34 \\
37.0 \%\end{array}$ & $\begin{array}{l}58 \\
63.0 \%\end{array}$ & $\begin{array}{l}92 \\
100 \%\end{array}$ \\
\hline $\begin{array}{ll}\text { Total } & \text { count } \\
& \text { \%within CKD }\end{array}$ & $\begin{array}{l}96 \\
56.5 \%\end{array}$ & $\begin{array}{l}74 \\
43.5 \%\end{array}$ & $\begin{array}{l}170 \\
100 \%\end{array}$ \\
\hline
\end{tabular}

[Table 3] shows the results, which are found statistically significant with $p$ value $<0.05$. The serum iPTH levels in CKD stage 3 patients, $51.9 \%$ patients had normal iPTH levels whereas in significant number $(48.1 \%)$ of patients, iPTH was elevated above normal range. In CKD stage 4 patients, $67.3 \%$ patients had iPTH above normal range and in only $32.7 \%$ patients, iPTH was normal. In CKD stage 5 patients, iPTH was normal in only $7.6 \%$ patients, $89.1 \%$ had high levels of iPTH and in $3.3 \%$ patients, it was below normal range.

\section{Table 3: The serum iPTH level in CDK3,4 and CDK5}

\begin{tabular}{|c|c|c|c|c|}
\hline & \multicolumn{3}{|c|}{ Intact parathyroid hormone } & \multirow[b]{2}{*}{ Tota } \\
\hline & $\begin{array}{l}\text { Below } \\
\text { normal }\end{array}$ & Normal & $\begin{array}{l}\text { Above } \\
\text { normal }\end{array}$ & \\
\hline $\begin{array}{cc}\text { CKD } 3 & \text { count } \\
& \text { \%within CKD } 3\end{array}$ & $\begin{array}{l}0 \\
0 \%\end{array}$ & $\begin{array}{l}14 \\
51.9 \%\end{array}$ & $\begin{array}{ll}13 \\
48.1 \%\end{array}$ & $\begin{array}{l}27 \\
100 \%\end{array}$ \\
\hline $\begin{aligned} \text { CKD } 4 & \text { count } \\
& \text { \%within CKD } 4\end{aligned}$ & $\begin{array}{ll}0 \\
0 \%\end{array}$ & $\begin{array}{l}18 \\
32.7 \% \\
\end{array}$ & $\begin{array}{l}33 \\
67.3 \% \\
\end{array}$ & $\begin{array}{l}51 \\
100 \%\end{array}$ \\
\hline $\begin{array}{cc}\text { CKD } 5 & \text { count } \\
& \% \text { within CKD } 5\end{array}$ & $\begin{array}{ll}3 \\
3.3 \% \\
\end{array}$ & $\begin{array}{l}7 \\
7.6 \% \\
\end{array}$ & $\begin{array}{ll}82 & \\
89.1 \% \\
\end{array}$ & $\begin{array}{l}92 \\
100 \% \\
\end{array}$ \\
\hline $\begin{array}{cc}\text { Total } & \text { count } \\
& \text { \%within CKD } \\
\end{array}$ & $\begin{array}{l}3 \\
1.8 \% \\
\end{array}$ & $\begin{array}{l}39 \\
22.9 \% \\
\end{array}$ & $\begin{array}{l}128 \\
75.3 \% \\
\end{array}$ & $\begin{array}{l}170 \\
100 \%\end{array}$ \\
\hline
\end{tabular}

Total alkaline phosphatase levels were within normal range in all patients of CKD stage 3. In stage 4 CKD patients, total ALP was within normal range in $94.1 \%$ patients and remaining $5.9 \%$ had high levels. In stage 5 CKD patients, ALP was above normal in $45.7 \%$ patients and normal in $54.3 \%$ patients( Table 4). The results are statistically significant. Similarly table 5 shows $25 \mathrm{OH}$ vitamin-D levels were below normal in $59.2 \%$ CKD stage 3 patients. Majority (70.6 \%) patients in CKD stage4 had low levels of $25 \mathrm{OH}$ vitamin-D and rest had normal levels. In CKD stage 5, 25 $\mathrm{OH}$ vitamin-D was low in $79.4 \%$ patients and in rest, it was normal. 
Table 4: Alkaline phosphatase levels in 3 different stages in CDK

\begin{tabular}{|c|c|c|c|}
\hline & \multicolumn{2}{|c|}{ Alkaline Phosphatase } & \multirow[b]{2}{*}{ Total } \\
\hline & $\leq 310$ & $>310$ & \\
\hline $\begin{array}{c}\text { CKD } 3 \text { count } \\
\\
\text { \%within CKD } 3\end{array}$ & $\begin{array}{l}27 \\
100 \%\end{array}$ & $\begin{array}{l}0 \\
0 \%\end{array}$ & $\begin{array}{l}27 \\
100 \%\end{array}$ \\
\hline $\begin{array}{cc}\text { CKD } 4 & \text { count } \\
& \text { \%within CKD } 4\end{array}$ & $\begin{array}{l}48 \\
94.1 \%\end{array}$ & $\begin{array}{l}3 \\
5.9 \%\end{array}$ & $\begin{array}{l}51 \\
100 \%\end{array}$ \\
\hline $\begin{aligned} \text { CKD } 5 & \text { count } \\
& \% \text { within CKD } 5\end{aligned}$ & $\begin{array}{l}50 \\
54.3 \%\end{array}$ & $\begin{array}{l}42 \\
45.7 \%\end{array}$ & $\begin{array}{l}92 \\
100 \%\end{array}$ \\
\hline $\begin{array}{cc}\text { Total } & \text { count } \\
& \text { \%within CKD }\end{array}$ & $\begin{array}{l}125 \\
73.5 \%\end{array}$ & $\begin{array}{l}45 \\
26.5 \%\end{array}$ & $\begin{array}{l}170 \\
100 \%\end{array}$ \\
\hline
\end{tabular}

Table 5: 25 Hydroxy vitamin D in CDK3,4 and CDK5

\begin{tabular}{|c|l|l|l|l|}
\hline \multirow{2}{*}{} & \multicolumn{3}{|c|}{ 25 Hydroxy vitamin D } & \multirow{2}{*}{ Total } \\
\cline { 2 - 4 } & \multicolumn{2}{|c|}{$\mathbf{2 0}-\mathbf{3 0}$} & \multicolumn{1}{|c|}{$>\mathbf{3 0}$} & \\
\hline CKD 3 count & 8 & 8 & 11 & 27 \\
\%within CKD & $29.6 \%$ & $29.6 \%$ & $40.8 \%$ & $100 \%$ \\
\hline CKD 4 count & 19 & 17 & 15 & 51 \\
\% within CKD & $37.2 \%$ & $33.3 \%$ & $29.5 \%$ & $100 \%$ \\
\hline CKD 5 count & 44 & 29 & 19 & 92 \\
\%within CKD & $47.8 \%$ & $31.6 \%$ & $20.6 \%$ & $100 \%$ \\
\hline Total count & 71 & 54 & 45 & 170 \\
\%within CKD & $41.8 \%$ & $31.8 \%$ & $26.4 \%$ & $100 \%$ \\
\hline
\end{tabular}

[Table 6] shows 8 patients of CKD stage 3, who have undergone X-ray, none had evidence of vascular calcification. Among 21 patients of CKD stage 4, only 1(4.8 $\%)$ had evidence of vascular calcification and 10(29.4\%) had evidence of vascular calcification out of 34 patients of CKD stage 5 patients. The results were found statistically significant with $\mathrm{p}$ value $<0.05$.

Table 7 shows 8 patients of CKD stage 3 who have undergone echocardiography, none had evidence of vascular calcification. Among 21 patients of CKD stage 4, all had evidence of vascular calcification and out of 34 patients of CKD stage 5 patients, 29(85.3\%) had evidence of valvular calcification.

Table 6: CKD Stage and vascular calcification
\begin{tabular}{|l|l|l|l|}
\hline \multirow{2}{*}{} & \multicolumn{2}{|c|}{ Vascular calcification } & \multirow{2}{*}{ Total } \\
\cline { 2 - 3 } & \multicolumn{1}{|c|}{ positive } & \multicolumn{1}{c|}{ negative } & \\
\hline CKD 3 & 0 & 8 & 8 \\
& $0 \%$ & $100 \%$ & $100 \%$ \\
\hline CKD 4 & 1 & 20 & 21 \\
& $4.8 \%$ & $95.2 \%$ & $100 \%$ \\
\hline CKD 5 & 10 & 24 & 34 \\
& $29.4 \%$ & $70.6 \%$ & $100 \%$ \\
\hline Total & $11 \%$ & 52 & 63 \\
& $19 \%$ & $81 \%$ & $100 \%$ \\
\hline
\end{tabular}

Table 7: CKD stage and valvular calcification

\begin{tabular}{|l|l|l|l|}
\hline \multirow{2}{*}{} & \multicolumn{2}{|c|}{ Valvular calcification } & \multirow{2}{*}{ Total } \\
\cline { 2 - 3 } & \multicolumn{1}{|c|}{ positive } & \multicolumn{1}{c|}{ negative } & 8 \\
\hline CKD 3 & 0 & 8 & $100 \%$ \\
\hline CKD 4 & $0 \%$ & $100 \%$ & 21 \\
& 0 & 21 & $100 \%$ \\
\hline CKD 5 & $0 \%$ & $100 \%$ & 34 \\
& 5 & 29 & $100 \%$ \\
\hline Total & $5.7 \%$ & $85.3 \%$ & 63 \\
& $7.9 \%$ & 58 & $100 \%$ \\
\hline
\end{tabular}

\section{Discussion}

The mean age of our study population was higher (50.5 years) to other studies by Agarwal SK et al (44 years), Sakuja V et al (46.2 years) and B. Ghosh et al (45.7 years). ${ }^{[5,6,7]} \mathrm{We}$ observed that males outnumbered females $(\mathrm{M}: \mathrm{F}=3: 1)$. There is male predominance among CKD population in most studies. In Nissenson's prevalence study from the United States, males had an overall prevalence of $1.6 \%$ and females $0.8 \%$, this twofold ratio was maintained at all levels of serum creatinine. ${ }^{[8]}$ Among Indian studies, Agarwal et al. ${ }^{[9]}$ showed a male prevalence of $48 \%$ among patients with serum creatinine more than $1.8 \mathrm{mg} / \mathrm{dl}$, while other hospital-based studies found males constituting 60$78 \%$ of CKD population ${ }^{[5,6,7]}$ One of the main reasons for these differences in may be that, in India, more males and younger persons attend hospitals than females and the elderly. MBDs are well described in patients with CKD. Agarwal et al described hypocalcemia in $29.9 \%$ and $49.6 \%$ in CKD stage 4 and 5, respectively, and hyperphosphatemia in $45 \%$ and $41.8 \%$, respectively. LaClair, et $\mathrm{al}^{[10]}$ found hypocalcemia in $8 \%$ and $28 \%$, and hyperphosphatemia in $20 \%$ and $50 \%$ of patients of CKD stages 4 and 5, respectively. In our study, hypocalcemia was found in 22.2 $\%, 33.3 \%$ and $48.9 \%$ cases of CKD stages 3,4 and 5 respectively. Hyperphosphatemia was found in $11.1 \%, 25.5$ $\%$ and $63.0 \%$ cases of CKD stages 3,4 and 5 respectively. Our study results corroborated with previous studies.

Total ALP also signifies high turnover bone disease when elevated and interpreted in appropriate circumstances. In this study, elevated ALP was present in 5.9\% and $45.7 \%$ of patients of CKD stage 4 and 5, respectively. Indeed, KDIGO recommended that the treatment of MBD be based on trend in changes of biochemical parameters rather than on abnormalities at a single point of time. B. ghosh et al found raised ALP in $43.59 \%$ and $76.66 \%$ of patients of CKD stage 4 and $5 \mathrm{D}$, respectively. Jabbar, et $\mathrm{al}^{[11]}$ found raised bone alkaline phosphatase in $60 \%$ of their stage 4 and 5 CKD patients. Vitamin D abnormalities were common in all CKD stages. $60-80 \%$ patients had low levels of 25 hydroxy vitamin D. 1,25-dihydroxyvitamin D deficiency is known to occur during the progression of CKD, because the final hydroxylation step of 25-hydroxyvitamin D to $25(\mathrm{OH}) 2 \mathrm{D}$ to $1,25(\mathrm{OH}) 2 \mathrm{D}$ is mediated by kidney $1 \alpha$-hydroxylase. Severity of deficiency did not correlate with CKD stage or other mineral abnormalities. In our study, the prevalence of deficiency of 25(OH)D3 increased as CKD progressed. Low $25(\mathrm{OH}) \mathrm{D} 3$ levels were found in $73.6 \%$ of patients. Jabber et $\mathrm{al}^{[11]}$ reported Vitamin D deficiency in $80 \%$, and insufficiency in $13 \%$ of the patients. B. Ghosh et al reported $83.13 \%$ of patients with CKD stage 4 and 5D had vitamin D level less than $30 \mathrm{ng} / \mathrm{mL}$. Our study results corroborated with these studies. Literature shows that, hyperparathyroidism presents early in CKD \& worsens with progression of CKD stages. There is an increase in the prevalence of hyperparathyroidism from CKD stage 4. Hyperparathyroidism was present in $67.3 \%$ patients in CKD stage $4 \& 89.1 \%$ patients in CKD stage 5 which was similar to Levin $\mathrm{A}$ et $\mathrm{al}^{[12]}$ study in which $56 \%$ patients in CKD with eGFR $<60 \mathrm{ml} / \mathrm{min}$ had hyperparathyroidism. Agarwal et al [5] found hyperparathyroidism in $57.8 \%$ of patients with CKD stage 4 and in $39.4 \%$ of patients with CKD stage 5 . Jabbar, et al. ${ }^{[11]}$

Observed prevalence of hyperparathyroidism in $60 \%$ of their patients of CKD stage 4 and 5. In our study, hyperparathyroidism was higher than other studies. Adynamic bone disease as evident by low iPTH levels was 
uncommon and found in $3.3 \%$ patients of stage 5 CKD. Vascular(abdominal aortic) calcification was seen in $4.8 \%$ and $29.4 \%$ in CKD stage 4 and 5 patients respectively. Shantha et $\mathrm{al}^{[13]}$ using a lateral abdominal X-ray for screening, found a prevalence of $76.9 \%$ in 26 Indian predialysis Stage 5 CKD patients who had a mean age of 56.6 years, $65 \%$ of whom were receiving calcium containing phosphate binders. A.T. Valson et $\mathrm{al}^{[14]}$ reported $6.8 \%$ of cases having vascular calcification. Valvular calcification was present in $14.7 \%$ of stage 5 CKD patients in our study, which is much lower than that reported in Caucasian predialysis CKD subjects (31\%) by Leskinen et al ${ }^{[15]}$ Ghosh et al., reported VC in $25 \%$ and $46 \%$ of Indian CKD Stage 4 and 5D patients respectively. A.T. Valson et a ${ }^{[14]}$ reported $96 \%$ of cases having valvular calcification. Among those having vascular or valvular calcification, most of the patients were older than 50 years and had evidence of hyperphosphatemia, hyperparathyroidism in comparison with those not having evidence of calcification.

\section{Conclusion}

In conclusion, we observed Low $25(\mathrm{OH})$ D levels, hyperparathyroidism, and hyperphosphatemia were the noticeable markers of CKD-MBD in our patients. Mineral bone disorder are common in CKD patients which start in early CKD stages \& worsen with disease progression that causes morbidity and decreased quality of life. Hence, this shows the importance of early recognition, understanding of their patho-physiological consequences \& planning management strategies to prevent their progression, thereby reducing the cardiovascular morbidity \& mortality.

\section{References}

1. Eknoyan G, Lameire N, Barsoum R, Eckardt KU, Levin A, Levin N, Locatelli F, Macleod A, Vanholder R, Walker R, Wang H. The burden of kidney disease: improving global outcomes. Kidney international $2004 ; 66(4): 1310-4$.

2. Banerjee S, Ghosh B, Brojen T, Singh N, Singh S, Sharma OP, et
al.The high prevalence of chronic kidney disease-mineral bone disorders: a hospital-based cross-sectional study. Indian J Nephrol 2012; 22: 285-291.

3. National Kidney Foundation. K/DOQI clinical practice guidelines for chronic kidney disease: Evaluation, classification, and stratification. Am J Kidney Dis 2002; 39 (Suppl 1):S1-S266.

4. Martin KJ, Gonzalez EA. Strategies to minimize bone disease in renal failure. Am J Kidney Dis 2001; 38:1430-1436.

5. Agarwal SK. Assessment of renal bone mineral disorder in naïve CKD patients: A single center prospective study. Indian J Nephrol 2007; $17: 96$

6. Sakuja V, Jha V, Ghosh AK, Ahmed S, Saha TK. Chronic renal failure in India. Nephrol Dial Transplant 1994; 9:871-2.

7. B. Ghosh, T. Brojen. The high prevalence of chronic kidney disease mineral bone disorders: A hospital based cross sectional study. Indian Journal of Nephrology 2012; $22: 285-291$.

8. Nissenson AR, Pereira BJ, Collins AJ, Steinberg EP. Prevalence and characteristics of individuals with chronic kidney disease in a large health maintenance organization. Am J Kid Dis 2001;37:1177-83.

9. Agarwal SK, Dash SC, Irshad M, Raju S, Singh R, Pandey RM. Prevalence of chronic renal failure in adults in Delhi, India. Nephrol Dial Transplant 2005;20:1638-42.

10. LaClair RE, Hellman RN, Karp SL, Kraus M, Ofner S, Li Q, et al. Prevalence of calcidiol deficiency in CKD: A cross-sectional study across latitudes in the United States. Am J Kidney Dis 2005; 45:1026-33.

11. Jabbar Z, Aggarwal PK, Chandel N, Khandelwal N, Sakhuja V, Jha V. Noninvasive assessment of bone mineral status in indian CKD population- a cross-sectional study. Indian J Nephrol 2007; 17:93.

12. Levin A, Bakris GL, Molitch M, Smulders M, Tian J, Williams LA, Andress DL. Prevalence of abnormal serum vitamin D, PTH, calcium, and phosphorus in patients with chronic kidney disease: results of the study to evaluate early kidney disease. Kidney international. 2007; 71(1):31-8.

13. Shantha GP, Kumar AA, Mancha A, Christopher M, Koshi R, Abraham G. Is abdominal aortic calcification score a cost-effective screening tool to predict atherosclerotic carotid plaque and cardiac valvular calcification in patients with end-stage renal disease. Indian J Nephrol 2012; 22: 431-7.

14. Valson AT, Sundaram M, David VG, Deborah MN, Varughese S, Basu G, Mohapatra A, Alexander S, Jose J, Roshan J, Simon B. Profile of incident chronic kidney disease related-mineral bone disorders in chronic kidney disease Stage 4 and 5: A hospital based cross-sectional survey. Indian journal of nephrology. 2014; 24(2):97.

15. Leskinen Y, Paana T, Saha H, Groundstroem K, Lehtimäki T, Kilpinen $\mathrm{S}$, et al. Valvular calcification and its relationship to atherosclerosis in chronic kidney disease. J Heart Valve Dis 2009;18: 429-38.

Copyright: () the author(s), 2019. It is an open-access article distributed under the terms of the Creative Commons Attribution License (CC BY 4.0), which permits authors to retain ownership of the copyright for their content, and allow anyone to download, reuse, reprint, modify, distribute and/or copy the content as long as the original authors and source are cited.

How to cite this article: Behera TR, Mohanty B, Sahu A, Naik S, Mohanty JN. Prevalence of Mineral Bone Disorders in Chronic Kidney Disease Patients. Acad. J Med. 2019;2(2):60-63.

DOI: dx.doi.org/10.21276/ajm.2019.2.2.16

Source of Support: Nil, Conflict of Interest: None declared. 